\title{
CONTRADIÇÕES INSTITUCIONAIS, PRÁXIS E MUDANÇA DO CONTROLE GERENCIAL: ESTUDO DE CASO EM UMA COOPERATIVA
}

\author{
Carlos Eduardo Facin Lavarda ${ }^{1}$ \\ Fabiane Popik ${ }^{2}$
}

Resumo: O estudo teve por objetivo identificar como as contradições institucionais e as práxis impulsionaram o processo de mudança do controle gerencial em uma Cooperativa de Santa Catarina, Brasil. Especificamente, verificou-se as contradições institucionais que impulsionaram a implementação do planejamento estratégico e o papel das práxis humanas para que este artefato de controle gerencial fosse institucionalizado na cooperativa pesquisada. Para tal, a pesquisa caracterizou-se quanto aos objetivos como descritiva, quanto ao procedimento estudo de caso, com abordagem qualitativa. As informações foram coletadas por meio de entrevistas com os diretores, gerentes e consultor da empresa, assim como documentos e observações no objeto de estudo. Foram coletadas dez entrevistas na sede da cooperativa, com duração de aproximadamente uma hora cada entrevistado, no período de fevereiro e março de 2013. Identificaram-se duas fontes de contradições: ineficiência dos controles gerenciais realizados pela cooperativa e desalinhamento de interesses entre gerentes e dirigentes, assim como entre gerentes do mesmo nível hierárquico, permitindo inferir que foram estas contradições institucionais que estimularam a mudança no objeto pesquisado. Quanto às práxis humanas, concluiu-se que estas são elementos necessários para que a mudança ocorra, pois são os intermediadores do processo. No que se refere aos agentes de mudança, foram identificados como tal os diretores, o consultor e os gerentes. No entanto, com base nos relatos dos entrevistados pode-se concluir que a implementação do planejamento estratégico na cooperativa está institucionalizado, sendo as contradições institucionais as principais impulsionadoras da mudança e as práxis os elementos necessários para que a mudança ocorresse.

Palavras-chave: Contradições Institucionais. Práxis Humanas. Mudança Institucional.

\footnotetext{
E-mail: elavarda@gmail.com - Bolsista CNPq - Universidade Federal de Santa Catarina

2E-mail: fabiane.popik@faculdadelasalle.edu.br - Faculdade La Salle de Lucas do Rio Verde/MT

- DOI: http://dx.doi.org/10.14392/asaa.2016090201

- Projeto de pesquisa financiado pelo Conselho Nacional de Desenvolvimento Científico e Tecnológico - "National Counsel of Technological and Scientific Development" Artigo recebido em 22/06/2015. Revisões requeridas em: 05/04/2016 e aprovado em 20/06/2016.
} 


\title{
INSTITUTIONAL CONTRADICTIONS, PRAXIS AND CHANGE MANAGEMENT CONTROL: A CASE STUDY FROM A COOPERATIVE
}

\begin{abstract}
The study aimed to identify how institutional contradictions and praxis boosted the process of management control change in a Cooperative of Santa Catarina, Brazil. Specifically, was searched the institutional contradictions that drove the implementation of strategic planning and the role of human praxis in the institutionalization of this management control artifact in the cooperative researched. To this end, the research was characterized as descriptive, case study procedure with a qualitative approach. Data were collected through interviews with directors, managers and consultant to the company, as well as documents and observations on the object of study. Ten interviews were collected at the headquarters of the cooperative, lasting approximately one hour each interviewee, between February and March 2013. Were identified two types of contradictions: inefficiency of management controls carried out by the cooperative and misalignment of interests between managers and leaders and between managers of the same hierarchical level; it can be inferred that these institutional contradictions stimulated change in the object searched. As regards human praxis, it was concluded that these elements are necessary for change to occur; they are the intermediaries in the process. With regard to the change agents were identified as such directors, managers and consultant. However, based on reports of respondents, can be concluded that the implementation of strategic planning in the cooperative was institutionalized and institutional contradictions major driving change and praxis were elements necessary for change to occur.
\end{abstract}

Keywords: Institutional Contradictions. Human praxis. Institutional Change. 


\section{INTRODUÇÃO}

A s novas práticas de gestão disponíveis às organizações, assim como a crescente competitividade entre os mercados e os avanços da tecnologia de informação, têm sido fatores que instigaram as organizações às mudanças em seus controles gerenciais, visando melhores resultados (BURNS; SCAPENS, 2000).

Estudos voltados às mudanças na gestão e nos controles gerenciais têm sido desenvolvidos (Burns; Scapens, 2000; Zan, 2006; Aguiar \& Guerreiro, 2008; Boff, Beuren \& Guerreiro, 2008; Lavarda, Ripoll \& Barrachina, 2009; Beuren; Macohon, 2010; Scott, 2010; Rezende \& Ichikawa, 2011), porém, comparativamente pouca atenção tem sido dada para estudos que analisam o processo de mudança nos controles gerenciais sob o enfoque das contradições institucionais.

A perspectiva descrita por Seo e Creed (2002) pautada nas contradições e práxis, permite explicar quando, como e porque os agentes podem vir a contestar e, posteriormente, efetuar mudanças institucionais em suas crenças, sistemas e controles, aceitando outras formas de fazer como sendo certas (Burns \& Baldvinsdottir, 2005).

Wanderley $(2012$, p. 4) destaca que as "contradições são as forças motrizes essenciais da mudança organizacional, mas elas não levam inevitavelmente a mudança institucional". Apesar das contradições serem as impulsionadoras para a mudança, Burns e Baldvinsdottir (2005) destacam que as práxis desempenham papel fundamental no processo de institucionalização dos processos, pois são estas que realizam tal mudança.

As mudanças nos controles gerenciais ocorrem, tanto nas organizações com fins lucrativos como em organizações sem fins lucrativos. As Cooperativas, consideradas como entidades sem fins lucrativos, apresentam características organizacionais diferenciada das empresas societárias, visto que constituem um conjunto específico de distribuição dos direitos de propriedade, poder de decisão e ganhos residuais entre seus membros (Bialoskorski Neto, Barroso \& Rezende, 2012). Considerando que em Cooperativas, cada membro, associado, tem direito unitário de decisão em assembleia, em que as decisões estratégicas são delineadas, juntamente a diretores e gestores, nota-se uma pluralidade de agentes envolvidos na gestão, o que tende a ampliar a possibilidade de conflitos, a diversidade de objetivos, demandando assim, controles gerenciais eficientes.

Em Cooperativas, são poucas as pesquisas voltadas aos controles gerencias (Almeida et al., 2009), e voltadas especificamente a mudanças nos controles gerenciais não se identificou estudos nas bases pesquisadas, fator que motivou a realização de tal estudo. Outro fator motivador é devido à Cooperativa pesquisada encontrar-se em cenário de mudança em seus controles gerenciais, em prol de melhorias na gestão e em preparação a desafios futuros, ao qual vai ao encontro da temática em estudo.

Portanto, dentro do contexto proposto por Seo e Creed (2002) e considerando o cenário de mudanças nos controles gerenciais da organização objeto de estudo, tem-se o problema que norteia a pesquisa: Como as contradições institucionais e as práxis impulsionaram o processo institucionalização dos artefatos de controle gerencial em uma Cooperativa de Santa Catarina? O estudo objetiva identificar como as contradições institucionais e as práxis impulsionaram o processo de institucionalização 
de artefatos do controle gerencial em uma Cooperativa de Santa Catarina, assim como, verificar se as mudanças estão institucionalizadas no objeto de estudo.

Estudos têm sido desenvolvidos com o enfoque de verificar a institucionalização de processos, hábitos e rotinas na contabilidade gerencial (Macohon, 2008; Soutes, 2006; Zonatto, Rodrigues Jr. \& Lavarda, 2011); de verificar quanto às mudanças na contabilidade gerencial (Burns \& Scapens, 2000; Zan, 2006; Aguiar \& Gerreiro, 2008; Scott, 2010); porém, estudos que analisam o processo de mudança sob o enfoque das contradições institucionais tem obtido maior destaque em publicações internacionais (Seo \& Creed, 2002; Burns \& Baldvinsdottir, 2005; Abrahamsson \& Gerdin, 2006; Sharma, Lawrence \& Lowe, 2010; Conrad \& Uslu, 2012; Bjerregaard \& Lauring, 2012), e no âmbito nacional, somente a obra de Wanderley (2012).

O estudo contribui teoricamente, auxiliando no preenchimento da lacuna na literatura nacional sobre o tema proposto, e estendendo os estudos desenvolvidos sobre os processos de mudança institucional, baseados na visão dialética de Benson (1977) proposta por Seo e Creed (2002). O estudo contribui no entendimento de quando e como os atores chegaram ao ponto em que eles realmente decidiram rever seus controles gerenciais, e a dinâmica utilizada no processo de mudança na cooperativa pesquisada, pelos agentes envolvidos.

\section{MUDANÇAS INSTITUCIONAIS SOB O ENFOQUE DE SEO E CREED}

Em uma visão geral, subentende-se que a teoria institucional está voltada a embasar quanto às mudanças institucionais, pautada nos postulados e nas ações dos atores organizacionais advindas tanto interna quanto externamente às instituições (Wanderley, 2012). Porém, a teoria institucional é incapaz de responder a algumas perguntas, tais como: de qual contexto surge a necessidade de mudança? Quando e como os atores organizacionais reconhecem a necessidade de mudança? (Seo; Creed, 2002; Burns \& Baldvinsdottir, 2005; Wanderley, 2012).

Nesse aspecto, Seo e Creed (2002) fundamentados na perspectiva dialética desenvolvida por Benson (1977) apresentaram um quadro promissor para a compreensão desta lacuna ao qual a teoria institucional não havia contemplado, abordando a mudança institucional voltado a conceituar quando e como os atores chegaram ao ponto onde eles realmente decidiram rever o seu comportamento institucionalizado (Burns \& Baldvinsdottir, 2005; Abrahamsson \& Gerdin, 2006; Major \& Ribeiro, 2009). Benson $(1977$, p. 3) afirma que a "visão dialética é fundamentalmente comprometida com o conceito de processo". Para o autor, a teoria está focada na transformação dos processos através do qual um conjunto de arranjos dá lugar a outro.

Para melhor entendimento da institucionalização e do processo de mudança sob a perspectiva dialética delineada por Benson (1977), Seo e Creed (2002), apresentam a Figura 1, contendo os quatro princípios básicos: construção social, totalidade, contradições e práxis.

A construção social centra-se no processo social através do qual relações ordenadas e previsíveis são produzidas e reproduzidas, por meio de interações humanas que são dirigidas por interesses pessoais e poder, permitindo que os padrões sociais sejam gradualmente construídos (Seo \& Creed, 2002). No entanto, processos podem não ter sido planejados e estarem incoerentes com os acordos estabelecidos, ocasionando conflitos e consequentemente a mudança social (Benson, 1977).

A totalidade, segundo princípio básico do pensamento dialético, define que os fenômenos sociais devem ser estudados de forma relacionada às suas múltiplas interconexões (Benson, 1977). Seo e Creed 
(2002) complementam que neste princípio, qualquer estrutura social não é vista como um fenômeno isolado, abstrato, mas sim como parte de um todo maior, composta de múltiplas estruturas sociais interligadas que operam em diversos patamares e em vários setores.

A contradição refere-se "às diferentes rupturas e inconsistências, tanto entre quanto dentre os arranjos sociais estabelecidos" (Seo \& Creed, 2002, p.225). Os autores observaram ainda, que a construção social em curso produz uma matriz complexa de contradições e tensões ocasionando conflitos entre e dentre os sistemas sociais, o que pode em algumas circunstâncias mudar a ordem dos processos atuais.

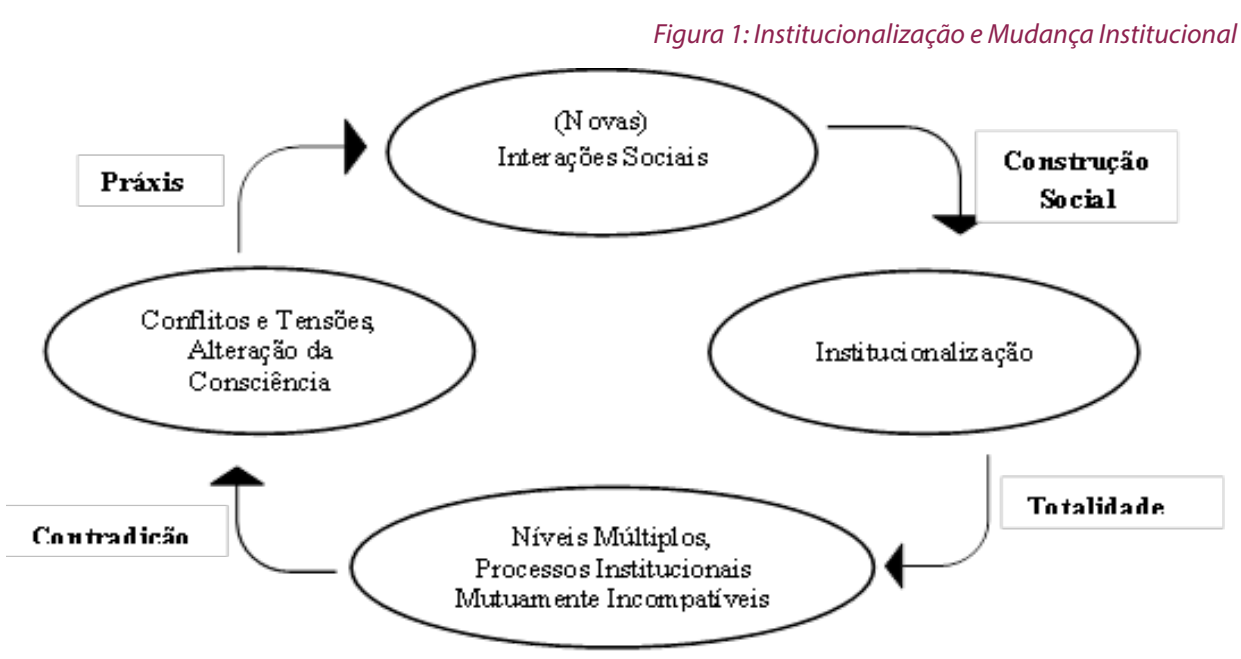

Fonte: Seo e Creed (2002, p. 225).

Por fim, o último princípio relacionado à perspectiva dialética, reporta-se as práxis. Benson (1977) descreve que a práxis é a livre e criativa reconstrução de arranjos sociais, fundamentada nos limites e nas potencialidades atuais das formas sociais, sendo as pessoas possíveis agentes ativos da reconstrução de suas próprias relações sociais.

A esse contexto, Seo e Creed (2002) destacam que nenhum desses quatro princípios - construção social, totalidade, contradição, práxis - podem ser entendidos separadamente, porém quando verificados em conjunto, constituem uma perspectiva global sobre o fundamental caráter da vida social.

\subsection{CONTRADIÇÕES INSTITUCIONAIS}

Os processos institucionalizados nas organizações, definidos e alinhados no princípio de construção social, podem conter dentre e entre seus arranjos, contradições, rupturas, inconsistências e incompatibilidades (Benson, 1977). As contradições geradas nos processos, causadas pelas incompatibilidades e desalinhamentos de interesses entre outros fatores, ocasionam as tensões e conflitos organizacionais (Benson, 1977; Seo \& Creed, 2002).

Seo e Creed (2002) observam que as contradições criam condições para a mudança, devido ao fato de gerarem conflitos e tensões entre atores organizacionais que acabam por despertar a necessidade de mudança institucional aos grupos e indivíduos. Esse mesmo entendimento é compartilhado por 
Burns e Nielsen (2006), ao complementarem que os grupos e indivíduos quando visualizam os efeitos das contradições percebem a necessidade de mudança.

Portanto, o contexto de contradição institucional, segundo Seo e Creed (2002) está atrelado as suas fontes de contradições, ou seja, de onde surgiram as necessidades de mudança, que segundo Seo e Creed (2002) são: ineficiência técnica, não-adaptabilidade, incompatibilidade institucional e desalinhamento de interesses. Os autores destacam ainda, que nem sempre as instituições irão produzir todos os quatro tipos de contradições, mas que geralmente estas tendem a produzir uma ou alguma combinação destes tipos de fontes de contradições.

Entre as premissas fundamentais da teoria institucional, abordadas por Dimaggio e Powell (1983) e também destacadas por Seo e Creed (2002), pauta-se que o sucesso organizacional depende de fatores além da eficiência técnica, como o aumento de legitimidade das organizações e de recursos necessários, a fim de tornar os ambientes da estrutura organizacional isomórficos. Como consequência, as práticas de contabilidade são utilizadas como símbolo, a fim de manter a aparência da legitimidade, e consequentemente acabam por ficarem dissociadas das atividades técnicas e dos processos administrativos (Wanderley, 2012). Nesse contexto, entende-se que as práticas contábeis, sob a perspectiva da organização devem suprir necessidades de legitimidade, e consequentemente atentar-se com menos intensidade no desempenho de suas técnicas.

Em consequências das ineficiências técnicas entre outros fatores, empresas tendem muitas vezes a mudar e ou implementar novos sistemas de controles. Porém, como abordado por Wanderley (2012), as contradições podem surgir também da não-adaptabilidade destes arranjos institucionais implantados na empresa para com o ambiente externo.

Seo e Creed (2002, p. 228) resumidamente afirmam quanto a esta fonte de contradição que "embora a institucionalização é um processo adaptativo, uma vez no lugar, as instituições tendem a ser tanto psicologicamente quanto economicamente bloqueados e, em certo sentido podem não responderem a estas mudanças em seus ambientes externos"

Portanto quando os processos não se adaptam às organizações, estas não conseguem responder as necessidades do ambiente e do contexto, consequentemente sendo uma fonte de contradição, ou seja, de possíveis conflitos e tensões dentre os arranjos sociais institucionalizados.

A terceira fonte de contradição está relacionada à incompatibilidade institucional. O princípio dialético da totalidade aborda que as organizações são compostas por múltiplos níveis organizacionais e setores interligados entre si (Seo \& Creed, 2002). Devido à produção e reprodução contínua de interações sociais serem realizadas na organização como um todo, "a conformidade com determinados arranjos institucionais dentro de um patamar específico ou setor pode causar conflitos ou inconsistências com os arranjos institucionais de patamares ou setores diferentes" (Seo \& Creed, 2002, p. 228).

A incompatibilidade, segundo Clemens e Cook (1999) também podem vir de dentro de um ambiente institucional, por exemplo, quando ocorre inovação. Nesse aspecto, observa-se que a incompatibilidade institucional, ocorre quando sistemas que foram institucionalizados acabam entrando em conflitos com sistemas e ou controles alternativos.

Do ponto de vista dialético, Seo e Creed (2002) destacam que a semente da mudança institucional se desenvolve a partir de uma das principais fontes de contradições institucionais: o desalinhamento de interesse entre os arranjos sociais existentes e os interesses e necessidades dos atores que constituem essas regras.

Neste caso, os atores cujas ideias e interesses não são adequadamente atendidos pelos arranjos sociais existentes, em algumas circunstâncias, acabam por se conscientizar e identificar as condições 
que não estão lhe satisfazendo e tomam medidas voltadas as mudanças institucionais (Seo \& Creed, 2002). Assim, a contradição de desalinhamento de interesses baseia-se em potenciais adversários institucionais, cujos interesses e ideias não são adequadamente atendidas pela ordem existente.

\subsection{PRÁXIS}

A perspectiva dialética adota a visão que as contradições institucionais são as forças impulsionadoras para que a mudança organizacional ocorra, mas não adota o pressuposto de que essas contradições levam impreterivelmente para tal mudança (Seo \& Creed, 2002). Nessa perspectiva, segundo os autores citados, as práxis humanas são caracterizadas como principais mediadores entre as contradições e a mudança institucional.

Benson (1977) descreve que a práxis se refere à reconstrução livre e criativa dos arranjos sociais, fundamentada nos limites e nas potencialidades de suas estruturas atuais. Práxis é a ação humana, de natureza política, que embora incorporada em instituições existentes, tendem a influenciar e garantir a mudança nos processos e arranjos institucionais (Seo \& Creed, 2002; Burns \& Baldvinsdottir, 2005).

Os atores organizacionais são os responsáveis por desenvolver as ações para que a mudança ocorra. Dentre as ações desenvolvidas por tais, destaca-se as reuniões, treinamentos, cursos, ação coletiva (Bruns \& Nielsen, 2006; Abrahamsson \& Gerdin, 2006; Sharma, Lawrence \& Lowe, 2010; Wanderley, 2012).

\section{METODOLOGIA}

No intuito de identificar as mudanças nos controles gerenciais institucionalizadas em uma Cooperativa de Santa Catarina, assim como as contradições que impulsionaram para tal mudança e as práxis envolvidas, delineia-se a pesquisa de forma descritiva, realizada por meio de estudo de caso, com abordagem qualitativa.

O estudo de caso realizado em uma Cooperativa Agropecuária, sendo a matriz situada no Oeste de Santa Catarina e com filiais localizadas na região oeste e litoral sul do estado, totalizando 25 unidades e 389 colaboradores em seu quadro de colaboradores no ano de 2012.

Em 2009 se iniciou o desenvolvimento do PAE - Programa Auriverde de Excelência, com o objetivo de aprimoramento do modelo de gestão e preparação da organização e das pessoas para os novos desafios do mercado. O Programa Auriverde de Excelência está fundamentado num sistema de trabalho prático e participativo, visando a constante melhoria da empresa em seus produtos, serviços, processos e consequentemente, resultados finais.

Devido à pesquisa buscar averiguar o processo de mudança no sistema de controle gerencial que foram institucionalizados, bem como as contradições e práxis envolvidas, dentre os vários módulos de controle gerencial em fase de implantação, pesquisou-se somente o módulo que apresenta indícios de já estar institucionalizado no objeto de estudo e que apresenta enfoque mais direcionado ao sistema de controle gerencial, ou seja, a pesquisa será pautada no planejamento estratégico.

O planejamento estratégico foi o primeiro dos módulos implementados na cooperativa por subentender que este forneceria a base para auxiliar os gestores nas suas tomadas de decisões e no planejamento para o futuro da cooperativa. Cabe considerar que antes da implementação deste módulo não existia nenhum sistema de controle gerencial no objeto de estudo pesquisado. 
Os instrumentos de pesquisa referem-se às técnicas utilizadas para coleta de dados. Richardson (2011) descreve que vários são os instrumentos de coleta de dados, como questionário, fichas, formulários, entrevistas, etc. $O$ instrumento utilizado é a entrevista, porém foram analisados também documentos do objeto de estudo (projeto de implantação PAE, cronograma de implantação, pautas de reuniões, relatórios gerenciais, e Demonstrativos contábeis) e procedidas observações a fim de melhor interpretar os resultados.

A entrevista foi delineada em blocos visando abranger questões que atendam a todos os objetivos da pesquisa, sendo que, inicialmente, busca-se a caracterização do entrevistado. Na sequência, verificam-se as categorias: a) contradições institucionais, buscando evidenciar quais foram as fontes que impulsionaram a mudança; b) práxis humanas, questionando-se quanto às ações dos agentes, investigando quem foram e qual foi o envolvimento destes no processo de mudança, e c) a mudança institucional, a fim de verificar quais mudanças ocorreram e como que foram institucionalizadas na organização.

A fim de apresentar a construção do instrumento de pesquisa, segue o Quadro 1 com o roteiro da pesquisa, contemplando os objetivos que se pretende responder, com as questões contempladas no instrumento de pesquisa, e os autores que foram a base para o desenvolvimento do instrumento.

Quadro 1: Roteiro de Entrevista

\begin{tabular}{|c|c|c|}
\hline Categorias & Questões da entrevista & Autores Base \\
\hline Caracterização & $\begin{array}{l}\text { 1) Qual seu cargo e sua função na Cooperativa? } \\
\text { 2) Quantos anos você ocupa o cargo atual na Cooperativa? } \\
\text { 3) Quantos anos você tem de Cooperativa? } \\
\text { 4) Qual sua formação acadêmica? } \\
\text { 5) Qual a sua idade? }\end{array}$ & Elaboração própria \\
\hline $\begin{array}{l}\text { Contradiões } \\
\text { institucionais }\end{array}$ & $\begin{array}{l}\text { 6) De onde surgiu a necessidade de implementar o planejamento } \\
\text { estratégico? } \\
\text { 7) Quais foram os fatores que motivaram a Cooperativa a } \\
\text { implementar o planejamento estratégico? } \\
\text { 8) No período anterior a implementação do planejamento } \\
\text { estratégico como era realizado este controle gerencial na } \\
\text { Cooperativa? } \\
\text { 9) Existia na Cooperativa algum outro sistema de controle gerencial } \\
\text { que desenvolvia os controles que atualmente são desenvolvidos } \\
\text { pelo planejamento estratégico? Qual? Como era procedido? } \\
\text { 10) Qual foi o momento em que foi percebido que realmente } \\
\text { era necessária mudanças no controle gerencial da Cooperativa? }\end{array}$ & $\begin{array}{l}\text { Seo, Creed (2002); } \\
\text { Burns, Baldvinsdottir, (2005); Abrahamsson, } \\
\text { Gerdin (2006); Sharma, Lawrence, Lowe (2010); } \\
\text { Wanderley (2012). }\end{array}$ \\
\hline $\begin{array}{l}\text { Práxis dos atores } \\
\text { organizacionais }\end{array}$ & $\begin{array}{l}\text { 11) Quem foram os agentes envolvidos no processo de mudança? } \\
\text { Eles permanecem na Cooperativa? } \\
\text { 12) São pessoas internas ou externas da Cooperativa? } \\
\text { 13) Qual é a formação acadêmica e profissional desses agentes? } \\
\text { 14) Eles tiveram alguma preparação, acadêmica, profissional } \\
\text { ou outra em específico, para desempenhar tais processos de } \\
\text { mudança? Qual? } \\
\text { 15) Quais as características do perfil profissionais dos agentes } \\
\text { da mudança? } \\
\text { 16) Na sua percepção as características do perfil profissional dos } \\
\text { agentes da mudança interferiu no processo de mudança? Por quê? } \\
\text { 17) Como eles foram capazes de implementar a mudança na } \\
\text { Cooperativa? } \\
\text { 18) Foi necessária a substituição de pessoas para que o plano de } \\
\text { mudança fosse desenvolvido? Quais pessoas foram substituídas? } \\
\text { Por que essas foram escolhidas? } \\
\text { 19) Quais foram os mecanismos de trabalho utilizados pelos } \\
\text { agentes para proceder à implementação do planejamento } \\
\text { estratégico? } \\
\text { 20) Como foi operacionalizado a implementação do planejamento } \\
\text { estratégico? } \\
\text { 21) Houve alguma resistência na implementação do planejamento } \\
\text { estratégico? Qual? Quais foram os motivos? }\end{array}$ & $\begin{array}{l}\text { Seo e Creed (2002); } \\
\text { Burns, Baldvinsdottir, (2005); Abrahamsson, } \\
\text { Gerdin (2006); Burns, Nielsen (2006); Sharma, } \\
\text { Lawrence, Lowe (2010); Conrad, Uslu (2011); } \\
\text { Wanderley (2012). }\end{array}$ \\
\hline
\end{tabular}




\begin{tabular}{|c|c|c|}
\hline $\begin{array}{l}\text { Institucionalização da } \\
\text { mudança no controle } \\
\text { gerencial }\end{array}$ & $\begin{array}{l}\text { 22) Após os processos de implementação do planejamento } \\
\text { estratégico terem sido encerrados, encontrou-se alguma } \\
\text { incompatibilidade, inconsistência com os sistemas que já estavam } \\
\text { sendo utilizados? Qual? } \\
\text { 23) O planejamento estratégico foi adotado e está sendo utilizado } \\
\text { por todos os usuários da Cooperativa? Na sua percepção qual a } \\
\text { intensidade deste uso? } \\
\text { 24) Após a implementação do planejamento estratégico, este } \\
\text { passou a fazer parte das rotinas diárias da Cooperativa? } \\
\text { 25) Como é possível perceber que o planejamento estratégico } \\
\text { faz parte das rotinas diárias da Cooperativa, ou seja, que ele foi } \\
\text { institucionalizado? }\end{array}$ & $\begin{array}{c}\text { Burns, Scapens (2000); Seo, Creed (2002) Burns, } \\
\text { Baldvinsdottir, (2005); Sharma, Lawrence, Lowe } \\
\text { (2010); Conrad, Uslu (2011); } \\
\text { Wanderley (2012). }\end{array}$ \\
\hline
\end{tabular}

Fonte: elaboração própria

O Quadro 2 descreve especificamente quem foram os sujeitos da pesquisa. Ao apresentar os sujeitos, destaca-se também uma abreviação do cargo do sujeito a fim de facilitar a análise dos dados.

Quadro 1: Sujeitos da pesquisa

\begin{tabular}{|c|c|}
\hline Cargo & Cargo \\
\hline Presidente da Cooperativa - PC & Gerente Regional Oeste - GRO \\
\hline Diretor Financeiro - DF & Gerente Regional Sul - GRS \\
\hline Diretor de Compras - DCP & Consultor - CS \\
\hline Diretor Comercial - DCM & Gerente de Unidade - GU1 \\
\hline Diretor Técnico - DT & Gerente de Unidade - GU2 \\
\hline
\end{tabular}

Fonte: elaboração própria

As entrevistas foram realizadas na sede da Cooperativa, no mês de fevereiro e março de 2013, sendo analisadas as informações do período em que se iniciou a mudança (2009) até o período atual, quanto à implementação do Planejamento Estratégico. Cabe destacar que foram coletadas informações, pareceres dos entrevistados, quanto ao período anterior ao início da mudança, visando evidenciar quais foram as contradições que impulsionaram a mudança e implementação do Planejamento Estratégico, bem como identificar quem foram os agentes envolvidos no processo. As entrevistas foram transcritas e aprovadas pelos entrevistados.

Além das entrevistas, foram coletadas informações nos demais documentos disponibilizados pela cooperativa em sites, relatórios, demonstrações, a fim de se obter validade à pesquisa por meio da triangulação de evidências. Foram analisados os demonstrativos de Demonstração de Resultado de Exercício, Balanço Patrimonial, relatório da administração dos últimos oito anos, a fim de averiguar sua posição e sua evolução no período.

Durante a coleta de dados, utilizou-se a técnica de observação para melhor interpretação das informações coletadas. Foram acompanhadas reuniões com os gerentes, com colaboradores, visitas a matriz e as filiais da cooperativa, a fim de acompanhar a institucionalização das mudanças. No processo de análise, as evidências recolhidas foram tratadas, codificadas e agrupadas conforme as categorias de análise propostas para o estudo.

A fim de possibilitar uma melhor interpretação das categorias de análise do estudo, apresenta-se a Figura 2, com o desenho da pesquisa. 


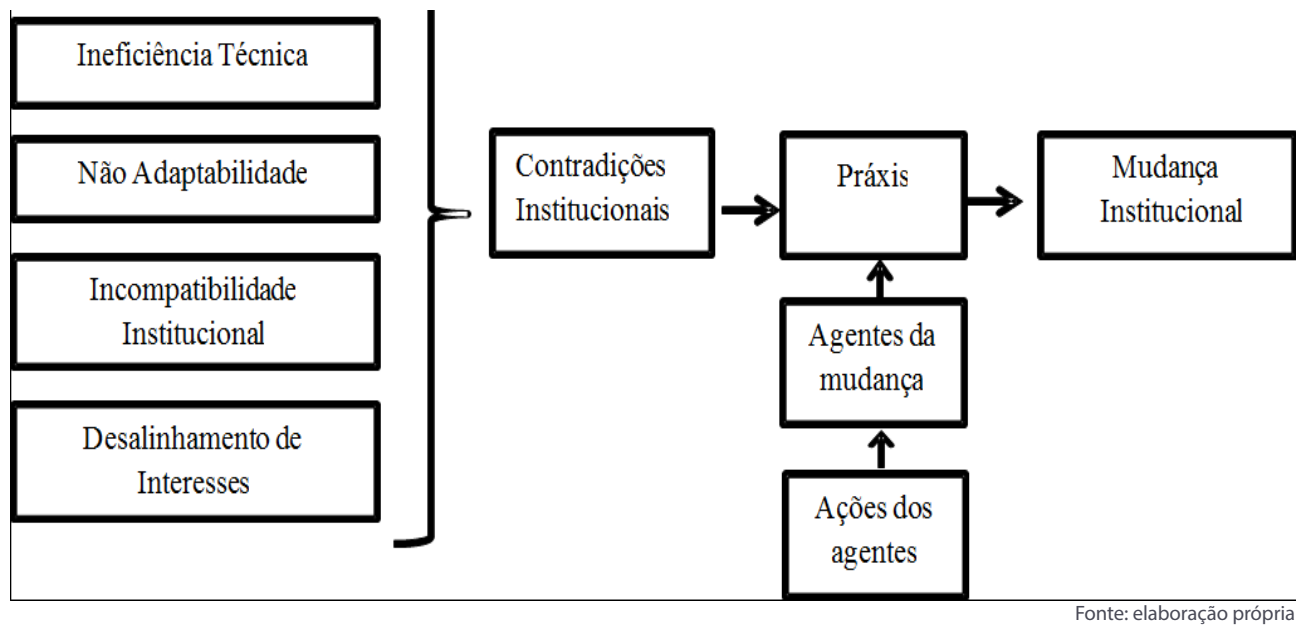

\section{ANÁLISE DOS RESULTADOS}

\subsection{CONTROLE GERENCIAL ANTES DA MUDANÇA}

Inicialmente, procurou-se entender por meio dos entrevistados, como os processos de controle gerencial eram realizados na cooperativa antes da mudança, ou seja, antes da implementação do planejamento estratégico.

No início como a cooperativa era menor se tinha o tempo da direção mesmo fazer o controle, mas em consequência do crescimento e do acúmulo de atividades e tarefas não foi mais possível que a direção somente tivesse o controle. Especificamente, antes da mudança o controle e o planejamento eram desempenhados somente pelo presidente e diretores, e aos demais gestores e associados eram repassadas as informações. Na época não se tinha pré-agendado reuniões para apresentação dos números e dos resultados do mês.

Os gestores responsáveis pelo controle gerencial analisavam o Balanço Patrimonial e a Demonstração do Resultado do Exercício, sem ter uma análise delineada por setor e ou por área de negócios da cooperativa. O presidente destaca a importância de se analisar o Balanço Patrimonial, e consequentemente a composição do ativo e passivo, visto que a maioria dos gestores se volta a focar somente da Demonstração do Resultado do Exercício, passando por despercebido na demonstração que muito representa para a organização.

No caso, era de responsabilidade da controller mensurar e gerar os relatórios e posteriormente repassar as informações à presidência e aos diretores. O problema é que nem sempre essas informações ficavam prontas e estavam disponíveis em tempo hábil para algumas tomadas de decisões. Portanto, percebe-se que antes da implementação do planejamento estratégico não se tinha informações de imediato e nem ferramentas que o permitissem obtê-lo. Os entrevistados ponderam que era difícil também porque se tinha os resultados gerais da cooperativa e não detalhado por áreas e atividades. Pode-se confirmar essa informação nos relatórios analisados, do período mencionado.

Isso não quer dizer que não havia metas delineadas anualmente, pois estas sempre existiram, o que acontecia como é observado por um dos entrevistados:"Na verdade todos nós tínhamos as metas, só que nós não parávamos para colocar no papel, para mensurar e colocar para o futuro o que se queria"(DCP). 
Um ponto importante destacado foi a questão dos setores, atividades que a Cooperativa que compõe a sua estrutura ao qual contempla: Agropecuária, Armazenagem e comercialização de Grãos, Fábrica de rações, Fábrica de Farinha, Laticínios, Posto de Combustível e Supermercados. Percebeu-se pelos entrevistados que estes setores eram analisados e planejados em um contexto só, sem serem observadas e pontuadas as suas particularidades. Nesse quesito foi observado por um dos respondentes que"não havia uma sistemática para analisar e acompanhar com mais precisão e exatidão os resultados da cooperativa e principalmente das suas diversas atividades, pois era analisado geral e não se tinha a divisão para ver o andamento dos resultados de cada uma destas áreas"(DT).

Com isso não se conseguia visualizar quais eram as atividades que realmente estavam sendo rentáveis e quais precisariam ser mudadas as estratégias a fim de obter melhores resultados. A falta de se ter um sistema que controlasse os resultados por área de negócio, por atividade, que permitisse aos gerentes o acompanhamento de quanto efetivamente haviam atingido de suas metas no período, fazia com que estes não se sentissem tão comprometidos como atualmente.

Considerando a ausência do controle por atividades e que a análise dos resultados do período acabava centrando-se na direção, os gerentes não tinham o conhecimento de quanto efetivamente estavam faturando em seus resultados e menos ainda de quanto ainda deveriam faturar para alcançar a meta geral do período. A preocupação e o controle ficavam somente sob responsabilidade dos diretores e presidente.

Os gerentes não tinham a responsabilidade de apresentar e justificar os valores que faturaram no mês, os lucros, os prejuízos, os desperdícios, as perdas, enfim isso somente era responsabilidade da direção. Devido a adoção dessa metodologia de trabalho, os gerentes de nível médio acabavam por preocupar-se em vender, sem interessarem-se pelo acompanhamento, e pelo quanto realmente estava resultando a venda.

Porém, foi ponderado pelos entrevistados que mesmo tendo as limitações da metodologia praticada, era perceptível que dentre o grupo de gerentes de nível médio, aproximadamente 25 colaboradores, alguns se destacavam e estavam mais engajados que outros, ou seja, mesmo estando sem os controles necessários preocupavam-se com as metas da cooperativa como um todo, visando sempre superá-las, enquanto outros não tinham essa mesma preocupação.

Conforme Burns e Nielsen (2006) destacam, os grupos e indivíduos quando visualizam os efeitos das contradições percebem a necessidade de mudança. Assim, diante do contexto da cooperativa, que identificou a falta de um controle eficaz, a ser utilizado por todos os agentes gestores, fez com que o presidente, juntamente com o conselho de administração e os diretores iniciaram o levantamento de informações e de procedimentos para a implementação de novos controles gerenciais na cooperativa. Notou-se também que nas pautas de reuniões essa era uma temática discutida entre gestores.

Porém, seguindo a vertente descrita por Seo e Creed (2002), as mudanças nas organizações são impulsionadas por contradições institucionais, em que o conceitua como tensões entre e dentro os arranjos institucionalizados.

\subsection{CONTRADIÇÕES INSTITUCIONAIS NA ORGANIZAÇÃO}

Ao iniciar a coleta de informações quanto aos motivos que impulsionaram a mudança nos controles gerenciais, pretendia-se entender se existiam e quais foram as contradições pertinentes na cooperativa e que impulsionaram a implementação do planejamento estratégico, como artefato de controle gerencial, dentro da perspectiva descrita por Seo e Creed (2002). 
O primeiro questionamento foi voltado a entender de onde surgiu a necessidade de mudança nos controles gerenciais na cooperativa. Percebeu-se que foi o fato de pensar no futuro, o foco nos controles, nos resultados por meio do estabelecimento de metas e objetivos devido ao crescimento econômico, financeiro e social da cooperativa que fez surgir a necessidade de implementação do planejamento estratégico. Cabe destacar que nos últimos 10 anos de história evoluiu de um faturamento anual de 58 milhões para 314 milhões exigindo um controle mais detalhado e uma gestão mais engajada para encarar os desafios e manter-se nesse percentual de crescimento no mercado competitivo.

Os diretores ponderaram que eles não estavam mais conseguindo olhar tudo, controlar tudo como eles faziam antigamente, porque o fluxo de negócios e atividades cresceram tanto que eles precisavam dividir a responsabilidade e também ter ferramentas para se organizarem de forma que continuassem a crescer. Esse crescimento foi possível verificar também nas Demonstrações Contábeis da cooperativa, que anualmente apresentava crescimento significativo em seus resultados.

Percebe-se então que houve uma ineficiência dos controles existentes, impulsionando a mudança, ou seja, até então havia controles, metas, havia o controle de metas, porém, sem uma formalização, tendo um foco voltado ao resultado global dos negócios da cooperativa, sem um acompanhamento imediato e por atividade, que permitisse uma análise dos resultados por área de negócios. Com isso, infere-se que a ineficiência técnica dos controles existentes foi a primeira contradição institucional que impulsionou a mudança na Cooperativa, de acordo com a perspectiva de Seo e Creed (2002).

Considerando que a metodologia proposta pelo planejamento estratégico possibilitava o alcance dessas necessidades e propósitos, buscou-se pela implementação de tal, pois ele continha os controles que no momento eram necessários a organização. $O$ artefato de controle foi implementado com a finalidade de se manter um controle formalizado, permitindo estabelecer metas e objetivos e principalmente de se ter um acompanhamento destes por área de atividade, assim como um delineamento do caminho adequado à se chegar.

O presidente pondera que a origem da mentalidade de planejamento começou a ser trabalhada em 2000 com alguns colaboradores, quando a implementação do Programa 5S, que tinha como foco a autodisciplina, ordenamento e planejamento. Nesse período até o ano de 2008, quando se iniciou a implementação do planejamento estratégico, mesmo o foco não sendo o mesmo, foi possível tanto os gestores se conscientizarem quanto conscientizar os colaboradores da importância de se fazer o planejamento para se ter melhores resultados.

Além da ausência de um sistema de controle efetivo, e talvez em consequência disso também, visualizava-se que havia gerentes de filiais e atividades mais comprometidos em alcançar as metas e os objetivos, e também gerentes sem esse engajamento todo. Alguns se preocupavam em acompanhar as metas, esforçavam-se para atender as demandas no contexto específico e geral, enquanto outros tinham a preocupação voltada somente a cumprir a obrigação básica cabível a função.

Nesse aspecto, também se percebia que a preocupação dos diretores estava em alcançar resultados financeiros positivos enquanto os gestores preocupavam-se em vender, sem avaliar quanto efetivamente isso estava sendo rentável à cooperativa. Com isso, infere-se que no objeto de estudo havia uma segunda contradição institucional descrita por Seo e Creed (2002) que impulsionou a mudança que foi o desalinhamento de interesses.

O desalinhamento de interesses visualiza-se no aspecto que os diretores estavam em busca de venda com resultados positivos, de controles, de acompanhamento de metas por meio dos demonstrativos contábeis que possibilitavam tal e os gerentes não estavam engajados e nem responsabilizados por 
esses acompanhamentos, mas sim estavam preocupados em vender, sem controlar se isso estava sendo lucrativo ou não, e o quanto já havia alcançado de suas metas.

Mais especificamente, como pontuado por um dos respondentes, havia desalinhamento de interesses entre as filiais de determinados setores, pois como a meta era geral e não distribuída por unidade, algumas estavam mais engajadas nos processos e outras menos, consequentemente não havendo uniformidade nos interesses dos gestores e colaboradores de uma mesma área de atividade. Esta contradição segundo Seo e Creed (2002), é a contradição que mais tende a impulsionar à mudança.

Com isso percebe-se que as contradições encontradas no estudo, tanto a ineficiência dos processos existentes, assim como o desalinhamento de interesses foram os fatores que motivaram para que a mudança ocorresse. Assim, os achados dão ênfase à Benson (1977), que enfatiza que os processos institucionalizados nas organizações, definidos e alinhados no princípio de construção social, podem apresentar contradições, e estas motivam a mudança.

Cabe destacar que se chegou a esses achados de forma subjetiva, pois em nenhum momento foi citado pelos autores que foi especificamente esses os motivos que instigaram a mudança, porém, pautado nas descrições dos fatos foi possível inferir que essas foram as contradições existentes na cooperativa. Pondera-se também que não se pesquisou a os agentes da cooperativa, pois pautou-se nos gestores.

Quanto às outras duas fontes de contradições delineadas por Seo e Creed (2002), não adaptabilidade e incompatibilidade institucional, não foram encontrados indícios de sua existência na cooperativa.

\subsection{PRÁXIS ENVOLVIDAS NA MUDANÇA INSTITUCIONAL}

Na pesquisa, ao que se refere às práxis humanas, se buscou identificar quem foram os envolvidos no processo de mudança, também caracterizados os agentes da mudança, para posterior busca das ações que foram desenvolvidas por estes para que efetivamente a mudança fosse institucionalizada.

No caso da Cooperativa, objeto de estudo, percebe-se que a mudança partiu do presidente que juntamente com o conselho de administração e a direção ao qual com o auxílio de um grupo de consultoria especializado na área de gestão de negócios e consequentemente em planejamento estratégico. Estas informações, estão destacadas nos relatórios de planejamentos das ações, sendo que o grupo de consultoria, representado especificamente por um consultor que se tornou responsável pelo desenvolvimento das atividades, foi quem delineou e apresentou a metodologia a ser adotada para a implementação do artefato de controle gerencial, assim como aos demais módulos de trabalho do Programa Auriverde por Excelência.

Ao questionar as principais práxis quanto ao seu conhecimento e experiência com o planejamento estratégico, percebeu-se que todos de alguma forma obtiveram algum contato com a ferramenta de controle implementada. O presidente havia participado de um curso em uma Universidade de renome e nessa ocasião pode expandir seus conhecimentos quanto ao artefato. Alguns diretores conheciam na teoria, devido a terem estudado na graduação e ou em sua formação acadêmica e outros ainda de experiências vividas em outras empresas.

O presidente ponderou que foi importante estudar com cuidado na hora de optar por qual metodologia de planejamento adotar, visto que a Cooperativa é composta por várias pessoas, tem um contexto um tanto quanto diferenciado das empresas comerciais, pois envolve conselho de administração, associados e um grupo significativo de colaboradores. Então tinha que se pensar em uma forma de planejar de maneira que todos aderissem a ferramenta e principalmente que está fosse utilizado por todos. 
Esse foi um dos motivos também que impulsionou a contratação de uma consultoria externa, pois via se nela uma alternativa de conhecimento e de experiências que poderia auxiliar na escolha e na implementação adequada ao contexto do objeto de estudo. A consultoria era uma das práxis que mais conhecimento tinha quanto ao processo que estava em adaptação, e isso foi visualizado pelos entrevistados: "O consultor tinha bastante conhecimento, porém o pessoal interno tinha conhecimento de experiências do dia a dia, de outras empresas que eles já tinham trabalhado, mas todos sabiam do que se tratava" (DCP).

Portanto, percebeu-se que o planejamento estratégico iniciou o alinhamento de suas estratégias na direção, para somente mais tarde ser aplicada às filiais. A direção, que era composta pelo presidente, vice-presidente, controller, diretor financeiro, diretor de compras, diretor comercial, reuniu-se juntamente com o consultor por várias vezes, desenvolvendo reuniões, em busca de uma preparação para que o processo fosse colocado em prática.

Cabe destacar que além do presidente, caracterizado por ter uma visão estratégica do negócio e ser um dos principais agentes dessa mudança, a contabilidade e o financeiro foram os setores que mais tiveram ligação com o consultor para o delineamento do artefato de gestão, visto que nestes constavam a base de informações, necessária para que o mecanismo fosse estruturado.

Foram desenvolvidas várias reuniões entre os agentes da mudança, como se pode verificar nos documentos apresentados. As reuniões tiveram como pauta, o desenvolvimento e alinhamento de planilhas, aulas teóricas sobre o tema, estratégias para colocar o planejamento estratégico em prática. Além de reuniões, várias conversas em particular com os diretores foram necessárias, sendo estas muitas vezes informais, a fim de identificar as dificuldades e necessidades que a Cooperativa tinha, visando supri-las assim como desenvolver um artefato de gestão eficiente.

Depois de alinhado os interesses entre o nível hierárquico da direção começou-se o trabalho com os gerentes, sendo este grupo composto por gerentes regionais, gerentes das áreas de negócios/atividades e gerentes de filiais, conforme destacado no cronograma de atividades. Iniciou-se o processo com reuniões. Um dos gerentes lembra que foram feitas aproximadamente dez reuniões para que o processo realmente fosse entendido por todos, sendo destas em torno de cinco somente de treinamentos operacionais, ou seja, práticas de como deveria ser procedido no dia a dia o uso do artefato gerencial do planejamento estratégico.

Para essas reuniões os processos já vieram prontos, ou seja, o consultor, juntamente com a direção, definiu as metas e os procedimentos e iniciaram o repasse das informações, visto que cada gestor tem uma ideia diferente e seria difícil alinhá-las todas naquele momento. Nas reuniões foram explicados onde coletar os dados que alimentam o sistema, quais informações deveriam ser analisadas, e como deveriam ser interpretadas.

No momento em que foi passado aos gerentes quanto ao artefato de controle gerencial, resistências surgiram, porém não houve a necessidade de mudanças de pessoas para que o processo fosse implementado.

Alguns gerentes chegaram deixarem seus cargos à disposição, não fazendo questão nenhuma de aderir à mudança. Para um diretor respondente a resistência é um tanto quanto pessoal, sendo que algumas pessoas acreditavam no artefato de controle e aderiram a este sem resistência, porém alguns tinham a percepção que o planejamento não era necessário e que seria um processo que somente iria tomar tempo e atrapalhar nas suas atividades normais. 
Houve também uma resistência ao quesito consultoria, pois se criou uma cultura por alguns diretores e gestores que a consultoria não auxiliava a organização, que era muito superficial e sem perspectivas futuras. Isso ocorreu devido a grupos anteriores de consultoria ter desenvolvido alguns trabalhos que não geraram resultados positivos, consequentemente manchando a imagem desses na instituição.

Porém, devido a essas resistências todas, o consultor entrou em campo, com conversas particulares, individuais, buscando alternativas para a mudança de posicionamento dos colaboradores. Foi relatado que as resistências não eram em grande quantidade, mas tinham um peso significativo para o contexto da mudança. Mesmo assim, não houve a necessidade de substituir pessoas para que o processo de mudança ocorresse.

Assim, foi possível perceber que algumas das pessoas que foram resistentes, mesmo continuando em suas funções, não vêm desempenhando os processos de planejamento estratégico como solicitado. Cabe destacar que a utilização do planejamento estratégico na cooperativa não foi imposta, não sendo estabelecida condição de "planeja ou sai", mas foi implantado pautado na conscientização de que seria um artefato necessário ao alcance de melhores resultados.

Porém ficou perceptível que as áreas em que houve adesão plena ao planejamento estratégico, houve resultado. Um dos entrevistados foi bem categórico ao afirmar que deveria ter sido feito realocação de pessoas para que o processo realmente fosse implementado com êxito num todo, porém isso não ocorreu.

Nota-se, segundo os entrevistados, que ainda hoje tem pessoas que ainda não sabem utilizar a ferramenta, aceitaram a mudança, mas não se esforçam para aprender e utilizar-se desta adequadamente. Consequentemente isso não contribui o quanto poderiam contribuir.

Cabe destacar que os gerentes não são todos iguais, cada qual tem suas habilidades, especificidades e características. Isso ficou visível com a implantação do planejamento estratégico, pois se identificou que tem indivíduos que se destacam em vendas, atendimento, porém não possuem perfil de controle, sendo estes os colaboradores que apresentaram mais resistência e dificuldades em aderir ao novo sistema de controle gerencial.

Assim, é notório que o consultor se destacou como um importante agente da mudança, pois além de articular estratégias de implementação, este teve o acompanhamento, conversas individuais com cada gerente a fim de verificar quais os problemas que estavam ocorrendo, visando minimizar as resistências e conflitos e principalmente buscar estratégias de alavancagem aos resultados.

Em 2010, depois de um ano do início da implementação do planejamento estratégico na cooperativa, foi trocado o grupo de consultoria. A troca de metodologia de certa forma impactou no andamento da implementação do planejamento estratégico, porém, acreditam os respondentes que a troca foi benéfica, pois a metodologia desta nova consultoria é mais maleável, mais acessível, ao contrário da metodologia do grupo anterior que estava mais pronta, mais imposta.

Os entrevistados observaram que o primeiro grupo de consultoria foi bom, tinha uma metodologia importante, porém a metodologia apresentada pelo segundo grupo estava mais de acordo com os objetivos que a cooperativa vinha buscando. "Ele tinha uma metodologia interessante, porém ele acabou ficando focado em aumento de vendas e não tanto o resultado econômico financeiro. Por isso a troca de consultoria, devido ao enfoque que o novo grupo apresentou a cooperativa" (GRS).

A metodologia de trabalho implantada pelo novo grupo de consultoria volta-se ao método. $\mathrm{O}$ consultor destaca que o objetivo deles não é somente planejar, mas sim ajudar a executar, criar uma 
sistemática de avaliação de resultado e tomada de decisão. Para tal, o grupo de consultoria anterior fazia o planejamento estratégico, mas não tinham método.

Os entrevistados ao avaliarem os grupos de consultoria, ponderam que tanto um grupo como o outro teve sua contribuição para que o artefato de controle gerencial alcançasse o objetivo e fosse implementado com sucesso, pois ambos tiveram como foco o aprimoramento da gestão, dos controles e dos resultados da cooperativa, cada qual com sua metodologia.

Portanto, percebeu-se que o processo de implantação do planejamento estratégico da cooperativa, as práxis definidas por Seo e Creed (2002), foram impulsionadas tanto por pessoas internas quanto externas da cooperativa. Porém, mesmo estando esse artefato em uso, ainda se faz necessário o acompanhamento das estratégias por parte dos agentes da mudança, visando melhores resultados para a Cooperativa como um todo.

Percebe-se então que os resultados apontam que as práxis, os agentes da mudança foram primordialmente o presidente e os diretores, ao qual ativamente e juntamente com o consultor e demais gerentes da organização, realizaram o processo implementação do novo sistema de controle gerencial.

Quanto as ações desenvolvidas pelos atores para a implementação do planejamento estratégico, as mesmas vão ao encontro das ações definidas por (Bruns \& Nielsen, 2006; Abrahamsson \& Gerdin, 2006; Sharma, Lawrence \& Lowe, 2010; Wanderley, 2012), visto que se destacou no estudo as reuniões, conversas individuais, treinamentos, visitas técnicas diretamente nas filiais, workshop, sendo todas as atividades voltadas a conscientizar e implementar o artefato de controle com eficácia.

\subsection{INSTITUCIONALIZAÇÃO DA MUDANÇA NA COOPERATIVA}

Até então se verificou que houveram contradições que impulsionaram a mudança e que as práxis tiveram importante papel no processo de implementação do planejamento estratégico, por terem sido os agentes responsáveis pela mudança, assim como por terem desenvolvidos mecanismos para operacionalizar os processos de implementação do planejamento estratégico. Cabe agora verificar como estão sendo desenvolvidos estes processos, se apresentam indícios de estarem institucionalizados e ou se foi uma mudança de insucesso, ou seja, verificar se o planejamento estratégico está ou não sendo tomado como rotina na cooperativa.

Inicialmente, buscou-se entender como estava sendo realizado o planejamento estratégico dentro da cooperativa depois de implementado este artefato de gestão. Os relatos apresentam que o planejamento vem sendo desenvolvido diariamente pelos gerentes juntamente com os seus colaboradores, sob cobrança da direção, que são os responsáveis pelo delineamento das metas a cada área de negociação e ou atividade da cooperativa, como se observa nas falas do Presidente e Consultor: "Hoje todos já utilizam do planejamento estratégico em suas atividades, sem resistência nenhuma” (PC)."Nota-se que a média gerência tem aderido e tem se utilizado muito bem ao planejamento estratégico, sendo que pode se dizer que a totalidade hoje trabalha com a ferramenta no dia a dia" (CS).

Os respondentes apontam que após a implementação do planejamento percebem-se os gerentes mais comprometidos com o processo e com os resultados da cooperativa, pois como as metas e resultados são definidos por área e também por filial cabe a cada um destes buscar e apresentar seus resultados perante a direção.

O planejamento estratégico é acompanhado diariamente pelos gerentes em suas áreas de negócios e a cada mês estes se reúnem com a direção e consultor para prestar contas de seus resultados e justificar 
suas ações. O Presidente (PC) destaca que depois de implementado o planejamento estratégico, todas as atividades têm suas metas, bem distribuídas e todas definidas pela cooperativa, e com ferramentas para acompanhamento. Então não se tem o porquê da direção e gestores fazer todo um trabalho e depois não acompanhar, conferir, gerenciar.

Para isso, se tem o acompanhamento mensal, em que todas as áreas têm seus responsáveis e cabe a cada um destes apresentar os resultados, os números e os índices alcançados, e se caso não tenha alcançado as metas do período, estes devem apresentar um plano de ação para corrigir a rota visando chegar na meta. Para o presidente, reunião sem apresentação de indicadores, de números não permite que seja gerenciado qualquer que seja o negócio.

Com isso percebe-se que está havendo um maior comprometimento e engajamento dos gerentes com os resultados da cooperativa, não sendo mais essa somente preocupação da diretoria. Como afirma o Diretor de Compras “Hoje o gerente se cobra a resultados e não é mais necessário que a direção fique cobrando e lembrando os gestores quanto às metas e resultados de suas unidades de atendimentos, de suas áreas de negócios, por que eles têm essas informações em mãos, sobre o seu controle" (DCP).

Nota-se que esse comprometimento se estendeu nas filiais, áreas de negócio, pois a maioria dos entrevistados além de participarem das reuniões com os diretores para apresentarem e justificarem seus resultados tem feito reuniões com a sua equipe visando melhorar as estratégias de negócios.

Quando questionado aos entrevistados se o artefato de controle gerencial, planejamento estratégico, estava sendo utilizado por todos os colaboradores na cooperativa, observou-se que as respostas foram unânimes, ou seja, todos estão utilizando, porém alguns com mais intensidade do que outros.

Foi ainda frisado por um dos respondentes que o planejamento se tornou uma rotina na cooperativa e tem trazido contribuições significativas, porém não ainda com a eficácia que se busca, pois, todos os colaboradores sabem que existe, mas nem todos ainda estão se posicionando em prol de busca de melhores estratégias com os dados e informações que tem a seu controle. Isso vai ao encontro da resposta de outro entrevistado que afirma conseguir identificar claramente onde houve a adesão e engajamento do gestor ao planejamento, pois nessas áreas já está se verificando resultados enquanto que em outras áreas ainda não teve resultado.

Segundo os entrevistados, isso também fica perceptível nas reuniões mensais de apresentação dos resultados, no sentido que algumas das atividades e ou filial que não estão conseguindo atingir as metas, aproveitam montam estratégias de ação para realizar o objetivo ainda não atingido e apresentam para discussão com os demais gerentes e diretores, em busca de melhorias, porém tem alguns gerentes que ainda não estão nesse engajamento. Nas áreas que acontecem o planejamento efetivo verifica-se o crescimento nos faturamentos e principalmente nos resultados.

Isso ocorre devido ao melhor acompanhamento das suas negociações, possibilitando informações a tempo hábil para as tomadas de decisões. No caso das atividades e ou produtos que estão tendo uma rentabilidade maior, amplia-se o foco visando maior faturamento do que os produtos que tem rentabilidade inferior. Outro ponto que o planejamento permite interpretação e visualização é das atividades que não estão rentabilizando quanto se almeja.

Esse foi o caso da atividade da suinocultura, que até então a cooperativa assumia todos os riscos e custos envolvidos à cadeia produtiva, porém, por meio do planejamento estratégico, percebeu-se que se estava muito dependente do preço de mercado e este muito volátil. Visto que nos últimos anos o prejuízo à cooperativa foi significativo iniciou-se a busca por alternativas de estratégia. Ao final do 
ano de 2012, iniciou-se uma parceria com uma agroindústria do ramo, ao qual repassou-se os riscos e custos envolvidos no processo em troca de uma rentabilidade menor, porém mais estável.

Em se tratando das fábricas de rações, por meio do planejamento estratégico percebeu-se que é uma atividade que apresenta rentabilidade significativa e que está crescendo constantemente, tanto em faturamento quanto em resultado. Partindo desses dados e informações, está sendo duplicada sua estrutura física e área de atuação visando alavancar os negócios dessa atividade.

No departamento de compras também tem prestado auxílio significativo, pois com a informação atualizada em mãos e a tempo hábil de quanto cada filial faturou no mês, as compras podem ser realizadas com mais exatidão, evitando que estoques fiquem sem movimentação, gerando prejuízos à organização.

O planejamento estratégico atualmente tem periodicidade anual, porém os entrevistados almejam chegar a desenvolver planejamento a longo prazo, projetando os próximos cinco anos de atividade da cooperativa. Porém, para que isso realmente seja desenvolvido é necessário que todos os colaboradores tenham um mesmo nível de intensidade de uso.

Ao contexto geral da cooperativa, um respondente apontou que após a implementação do planejamento estratégico, percebeu-se um novo controle de gestão e um novo cenário, bem mais organizado, controlado e preparado para responder as exigências do mercado competitivo. “Foi uma grande evolução para a cooperativa, devido a permitir uma melhor visão do negócio, permitindo visualizar qual atividade está mais rentável, qual está trazendo melhores resultados, e isso é devido aos números que o planejamento proporciona as tomadas de decisões" (GRS).

O Presidente afirmou: “O planejamento é uma ferramenta necessária e útil e não pode-se mais abrir mão dela, sendo que ainda precisa-se de aprimoramento, de melhorias, mas isso será constante visando sempre aperfeiçoar o que se tem, voltado a se ter um profissionalismo maior e consequentemente melhores resultados" (PC).

Portanto, considerando os posicionamentos, o conhecimento, a intensidade de uso por parte dos gerentes de nível médio assim como da diretoria, e as atividades que vem sendo desenvolvidas, como às reuniões e ações de acompanhamento de resultados, infere-se que o planejamento estratégico apresenta indícios de estar institucionalizado na cooperativa objeto de estudo, porém ainda precisa de melhorias como apontado por vários entrevistados.

\section{CONCLUSÕES}

O estudo teve por objetivo identificar as contradições institucionais e as práxis presentes no processo de mudança do controle gerencial em uma Cooperativa Agropecuária. Mais especificamente, buscou-se verificar quais foram às contradições que impulsionaram a implementação do planejamento estratégico e qual foi à contribuição das práxis humanas para que este artefato de controle gerencial fosse institucionalizado na cooperativa pesquisada, seguindo o modelo de análise proposto por Seo e Creed (2002).

Para tal, desenvolveu-se uma pesquisa descritiva, com abordagem qualitativa, por meio de entrevistas com os diretores, gerentes e consultor da cooperativa, objeto de estudo. Optou-se por este objeto de estudo devido à acessibilidade e principalmente pelo fato da cooperativa estar envolvida em processo de mudança ao qual é o foco da pesquisa. Foram coletadas dez entrevistas, com duração de aproximadamente uma hora cada entrevistado, sendo todas estas coletadas na sede da cooperativa no período de fevereiro e março de 2013. 
Os resultados indicam contribuições teóricas, ao corroborar e elucidar achados anteriores da literatura, e práticas, ao estudar um tipo organização que apresenta complexidade de gestão, para o estudo das contradições e da institucionalização de práticas de controle gerencial. As contradições institucionais que impulsionaram a mudança resultaram da ausência sistemática de um controle de acompanhamento dos resultados e metas da cooperativa por área de negócios e atividades, ocasionando a primeira contradição institucional, a ineficiência dos processos.

Também, foi evidenciado pelos respondentes que o desengajamento dos gerentes em prol de melhores resultados em suas áreas de atividades, tanto entre gerentes de um mesmo nível hierárquico quanto com a diretoria. Com isso, identificou-se a segunda e, possivelmente, mais consistente contradição institucional que foi o desalinhamento de interesses. Assim como nos estudos de Burns e Baldvinsdottir (2005) e Conrad e Uslu (2011), também se evidenciou que a ineficiência técnica e o desalinhamento de interesses foram as fontes de contradições que impulsionaram a mudança institucional, ou seja, que motivaram a implementação do planejamento estratégico na organização estudada.

A avaliação das práxis dos atores organizacionais revelou que os agentes envolvidos no processo de implementação do planejamento estratégico, foram o Presidente com o auxílio do consultor externo, que, em um segundo momento, em conjunto com os demais diretores, alinharam e estruturaram a metodologia de trabalho a ser repassada aos demais agentes. Os diretores envolvidos foram, o diretor financeiro, o controller, o diretor de compras e o diretor comercial. O grupo de gerentes era então composto pelos gerentes regionais, gerentes de área de atividades e gerentes de unidades.

Verificou-se, também, a institucionalização do planejamento estratégico na Cooperativa, cujos indícios apontam a utilização do artefato nas rotinas diárias da organização, especialmente no processo de tomada de decisões; além do mais, se realiza um acompanhamento mensal das metas por atividades e filiais, por meio de reuniões com diretores, ao qual cabe a cada gerente apresentar e justificar seus resultados.

É importante observar, como também encontrado no estudo de Conrad e Uslu (2011) que houve resistência por parte de alguns gerentes quanto à implementação do novo artefato de controle gerencial. Com isso, restou perceptível que nas atividades e ou nas filiais em que a resistência surgiu, os resultados não foram tão positivos quanto naquelas em que a adesão foi unânime.

Pode-se concluir, de acordo com a literatura descrita por Seo e Creed (2002), que as contradições institucionais, advindas das fontes de ineficiência dos controles gerenciais, assim como do desalinhamento de interesses dos gerentes e diretores, foram os fatores que impulsionaram a mudança do controle gerencial na cooperativa. Para tal, as práxis humanas foram os principais intermediadores do processo de implementação do planejamento estratégico, sendo estas representadas pela presidência, diretores, gerentes e consultor, desenvolvendo ações como reuniões, conversas individuais, treinamentos, visitas técnicas juntamente com os demais colaboradores. Contudo, quanto a institucionalização do planejamento estratégico, este apresentou indícios de estar institucionalizado de acordo com o entendimento de Burns e Scapens (2000).

Os resultados deste estudo despertam interesse para novas pesquisas sobre as contradições, práxis e contradições institucionais. Assim, recomenda-se incluir atores que não mais fazem parte das empresas estudadas, mas que atuaram no início da implementação do controle gerencial, assim como identificar os gestores que apresentaram resistências as mudanças, identificando seus motivos; e desenvolver estudos em organizações com as mesmas características a fim de comparar os achados e ampliar os estudos quanto à temática. 


\section{REFERÊNCIAS}

Abrahamsson, G. \& Gerdin, J. (2006). Exploiting institutional contradictions: The role of management accounting in continuous improvement implementation. Qualitative Research in Accounting \& Management, 3(2): pp. 126-144.

Aguiar, A. B. \& Guerreiro, R. (2008). Processos de persistência e mudança de sistemas de contabilidade gerencial: uma análise sob o paradigma institucional. Revista Universo Contábil, 4(3): pp. 06-24, jul./set.

Almeida, L. B., Machado, E. A., Raifur, L. e Nogueira, D. R. (2009). A utilização do orçamento como ferramenta de apoio à formulação de estratégia, de controle e de interatividade: um estudo exploratório nas cooperativas agropecuárias da região sul do Brasil. Revista Contabilidade Vista \& Revista, 20(3): pp. 65-99, jul./set.

Benson, J. K. (1977). Organizations: A Dialectical View. Administrative Science Quarterly, 22(1): pp.1-21.

Beuren, I. M. \& Macohon, E. R. (2010). Institucionalização de hábitos e rotinas na contabilidade gerencial em indústrias de móveis. Organizações \& Sociedade, 17(55), 7: pp. 705-723.

Bialoskorski Neto, S., Barroso, M. F. G. \& Resende, A. J. (2012). Governança cooperativa e sistemas de controle gerencial: uma abordagem teórica de custos da agência. BBR- BrazilianBussinesReview, 9(2): pp.72-92, abr./jun.

Bjerregaard, T. \& Lauring, J. (2012). Entrepreneurship as Institutional Change: Strategies of Bridging Institutional Contradictions. European Management Review, 9: pp.31-43.

Boff, M. L., Beuren, I. M. \& Guerreiro, R. (2008). Institucionalização de hábitos e rotinas da controladoria em empresas do Estado de Santa Catarina. Organizações \& Sociedade, 15(46), 8, pp. 153-174.

BURNS, J. \& Baldvinsdottir, G. (2005). An Institutional Perspective of Accountants' New Roles - the Interplay of Contradictions and Praxis. European Accounting Review, 14(4): pp.725-757.

\& Nielsen. K. (2006). How do Embedded Agents Engage in Institutional Change? Journal of Economics Issues, 40(2): pp.449-456.

.\& Scapens, R.W. (2000). Conceptualising management accounting change: an institutional framework. Management Accounting Research. 11: pp. 3-25.

Clemens, Elisabeth S. \& Cook, James M. (1999). Politics and institutionalism: Explaining durability and change. Annual Review of Sociology, pp. 441-466.

Conrad, L. \& Uslu, P. G. (2011). Investigation of the impact of 'Payment by Results' on performance measurement and management in NHS Trusts. Management Accounting Research, 22: pp. 46-55. 
Dimaggio, P. J. \& Powell, W. W. (1983). The iron cage revisited: institutional isomorphism and collective rationality in organizational fields, American Sociological Review, 48(2): pp. 147-160.

Lavarda, C. E. F., Ripoll, V. M. \& Barrachina, M. (2009). La Interiorización del Cambio de un Sistema Contable de Gestión en la Pequeña Empresa. Revista Contabilidade \& Finanças, USP, São Paulo, 20(51): pp. 101-115, setembro/dezembro.

Macohon, E. R. (2008). Reflexos da institucionalização de hábitos e rotinas organizacionais nos estágios evolutivos da contabilidade gerencial. Dissertação (Mestrado em Administração) - Programa de Pós-Graduação em Administração e Ciências Contábeis - Universidade Regional de Blumenau, Blumenau.

Major, M. J. \& Ribeiro, J. (2009). A teoria institucional na investigação em contabilidade. In: MAJOR, M. J.; VIEIRA, R. Contabilidade e Controlo de Gestão:Teoria, Metodologia e Prática. Lisboa: Escolar Editora, pp.37-59.

Rezende, G. M. \& Ichikawa, E. Y. (2011). O Contexto Ambiental e as Mudanças Organizacionais no Setor de C\&T Agrícola do Paraná. Desenvolvimento em Questão, 9(18), pp. 111-138.

Ribeiro, J. \& Scapens, R. W. (2006). Institutional theories in management accounting change: Contributions, issues and paths for development. Qualitative Research in Accounting \& Management, 3(2): pp. 94-111.

Richardson, R. J. (2011). Pesquisa social: métodos e técnicas. 3. ed. São Paulo: Atlas.

Scapens, R. W. (1994). Never mind the gap: towards an institutional perspective on management accounting practice. Management Accounting Research. 5: pp. 301-321.

(2004). Doing Case Study Research. In: Christopher Humphrey (Editor), Bill Lee (Editor). The Real Life Guide to Accounting Research: A Behind-the-Scenes View of Using Qualitative Research Methods, UK: Oxford.

Scott, W. R. (2010). Reflections: The Past and Future of Research on Institutions and Institutional Change. Journal of Change Management, 10(1): pp. 5-21.

Seo, M. \& Creed, W. (2002). Institutional contradictions, praxis, and institutional change: A dialectical perspective. Academy of Management Review, 27(2): pp.222-247.

Sharma, U., Lawrence S. \& Lowe, A. (2010). Institutional contradiction and management control innovation: A field study of total quality management practices in a privatized telecommunication company. Management Accounting Research, 21(4): pp. 251-264.

Soutes, D. O. (2006). Uma investigação do uso de artefatos da contabilidade gerencial por empresas brasileiras. Dissertação (Mestrado em Controladoria e Contabilidade) - Programa de Pós-Graduação em Ciências Contábeis da FEA/USP, São Paulo. 
Zan, A. (2006). Mudanças na contabilidade gerencial de uma organização: estudo de caso com diagnóstico institucional. Dissertação. (Mestrado em Ciências Contábeis) - Programa de Pós-Graduação em Administração e Ciências Contábeis - Universidade de São Paulo, São Paulo.

Zonatto, V. C. S., Rodrigues JR., M. M. \& Lavarda, C. E. F. (2011). Institucionalização de hábitos e rotinas em práticas orçamentárias: um estudo no Núcleo de Serviços Orçamentários de uma instituição de ensino profissional. In: Congresso Brasileiro de Custos, 18, Anais...Rio de Janeiro: ABC.

Wanderley, C. A. (2012). Institutional contradiction and the balanced scorecard: a case of unsuccessful change. In: Encontro Nacional da Associação dos Programas de Pós-Graduação em Administração, 37. 2012, Anais... Florianópolis: ANPCONT. 